\title{
Review
}

\section{Herpes simplex virus latent infection in the nervous system}

\author{
Israel Steiner ${ }^{1}$ and Peter GE Kennedy ${ }^{2}$ \\ ${ }^{1}$ The Laboratory of Neurovirology, Department of Neurology, Hadassah University Hospital, Hebrew University- \\ Hadassah Medical School, Jerusalem, Israel 91120; ${ }^{2}$ The Glasgow University, Department of Neurology, Institute of \\ Neurological Sciences, Southern General Hospital, Glasgow G51 4TF, UK
}

\begin{abstract}
Herpes simplex virus (HSV) establishes a latent infection in the human peripheral nervous system and can cause recurrent disease by reactivation. Intensive effort has been directed in recent years to unveil the molecular, cellular and immune mechanisms, as well as the virus-host interactions associated with latent HSV infection. The aim of this review is to summarize current knowledge regarding the site of latent infection, the molecular phenomena of latency, and the mechanisms of the various stages of HSV-1 latent infection in the nervous system, relating them where possible to the human situation. Specifically, the following biological questions are addressed: (1) How does this lytic virus survive in the nervous system and why can it establish a lifelong latent infection in nerve cells? (2) What advantage is conferred on HSV by establishing latent infection in nervous tissue? (3) What can be gathered from the accumulated knowledge on latency about the pathogenesis of herpes simplex encephalitis?
\end{abstract}

Keywords: herpes simplex virus; latent infection; viral pathogenesis; nervous system; gene expression

\section{Introduction}

The ability of herpes simplex virus type 1 (HSV-1) to colonize and establish latent infection in the human nervous system has attracted much scientific interest ever since Goodpasture postulated in 1929 that the recurrent mucocutaneous disease stems from a dormant viral state in the peripheral sensory ganglia (PSG). Half a century later, Stevens and colleagues (Stevens and Cook, 1971; Cook and Stevens, 1973) as well as other groups (Bastian et al, 1972; Baringer and Swoveland, 1973) established the validity of this hypothesis by isolating HSV from human PSG. Recent years have witnessed a plethora of data on the molecular concomitants of HSV latency (for reviews see Roizman and Sears, 1987; Stevens, 1989; Steiner and Kennedy, 1993) and the information so gathered in this field has now paved the way for the use of HSV-derived vec-

Correspondence: I Steiner

Received 30 September 1994, revised 31 October 1994, accepted 2 November 1994 tors as vehicles for gene therapy in neurological disorders (Kennedy and Steiner, 1993). While it is possible that there are sites of extraneural HSV latency (Clements and Subak-Sharpe, 1988; Abgharis and Stulting, 1988; Stevens, 1978; Kaye et al, 1991), it is widely accepted that HSV latency is an almost exclusive feature of nervous tissue.

The aim of this review is to summarize current knowledge on HSV-1 latent infection and to examine its relevance to human disease. Specifically, we will address the following questions: (1) By what mechanisms does this lytic virus survive in the nervous system and how can it establish a lifelong latent infection in nerve cells since the usual outcome of most viral infections is either destruction of the host, or elimination of the viral pathogen from the organism? (2) What is the relevance of the accumulated experimental data on latency to the pathogenesis of HSV-1-induced disease in humans? (3) What advantage is conferred on the virus by establishing latency in nervous tissue? In this rather controversial field, considerable differences may exist 


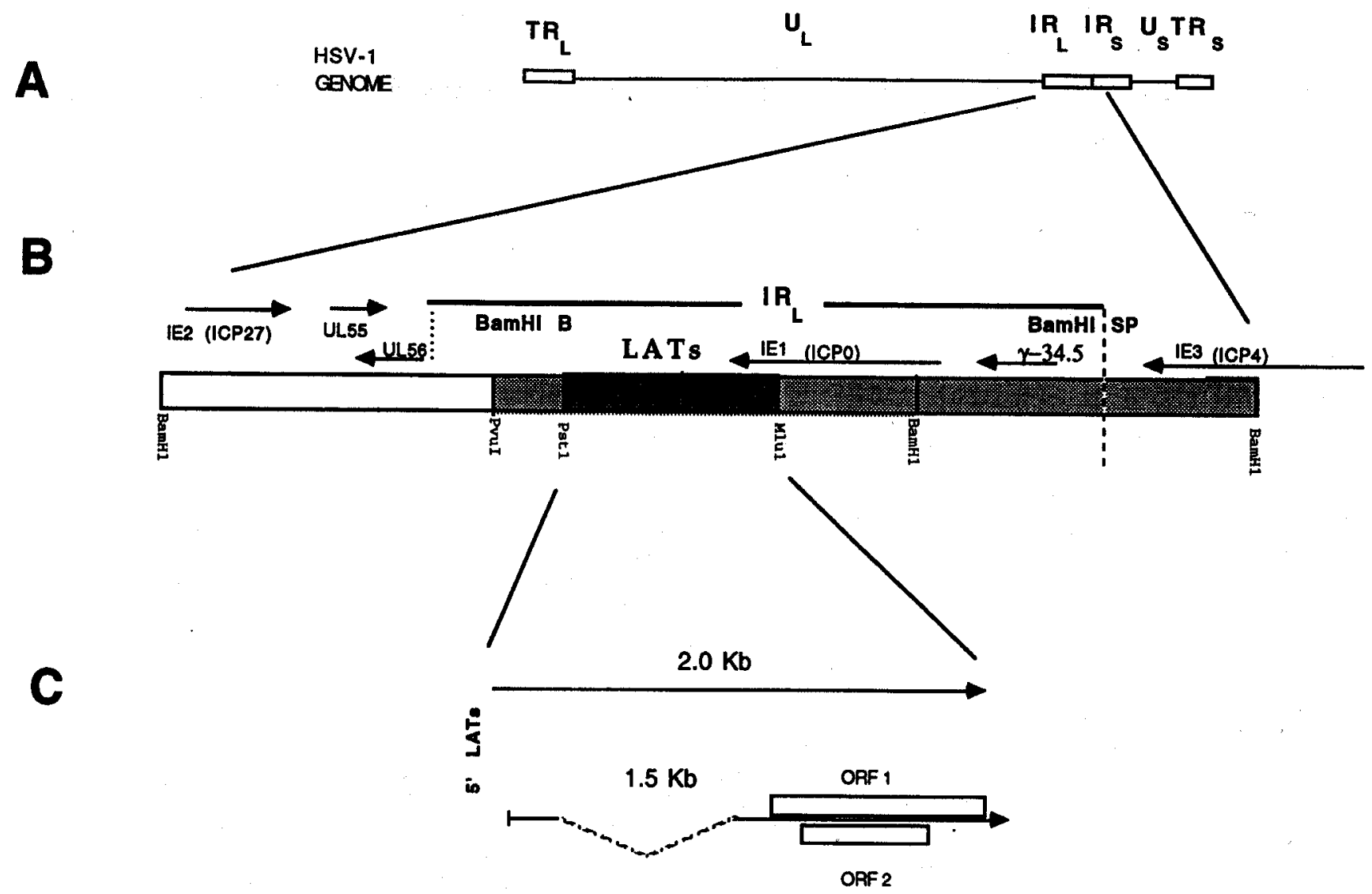

Figure 1 Herpes simplex virus type 1 (HSV-1) genome organization, location and structure of the viral latency-associated gene expression. (a) The HSV-1 genome illustrating the unique long $\left(U_{L}\right)$ and unique short $\left(U_{S}\right)$ regions bounded by the terminal and internal repeat regions (TR and IR respectively). (b) Detailed map of BamHI restriction fragments B and SP. The approximate location of the immediate early (ICP4, ICPO and ICP27) and other ( $\gamma-34.5$, UL55 and UL56) genes' mRNAs clustered in this fragment of the viral genome are marked by arrows that indicate their transcription orientation. The region of the viral genome that is transcriptionally active during HSV-1 latent infection and is positive by in situ hybridization is shaded. The darkly shaded region between PstI and MluI restriction sites gives rise to two overlapping HSV-1 LATs. Also denoted are the location of the internal repeat long (IR $\mathrm{L}_{\mathrm{L}}$ ) and the border between the long and short fragments of the genome. (c) Map and structure of the LATs. The $5^{\prime}$ and $3^{\prime}$ ends of the LATs, and the location of the open reading frames (ORFs) are illustrated.

in the individual researcher's interpretation of some of the data. While attempting to provide an overview of HSV latency, we have inevitably formulated our own views which do not necessarily conform with current established dogmas.

\section{Background}

\section{Definition of latency}

Latent infection is defined as the presence of the viral genome in the tissue without production of infective viral particles. However, the virus maintains the potential to reactivate, resume replication and cause recurrent disease. In the case of HSV-1, molecular criteria must be added to this definition since, as will be discussed, during latency, the structure of the viral DNA and the pattern of its gene expression differ from the situation present during viral replication in cell culture.

\section{Animal models}

The greater volume of information pertaining to latency of the neurotropic herpesviruses stems from studies with HSV-1 in experimental animals. Subsequently the data were substantiated on human tissue and findings were also later extrapolated to studies using HSV-2 (Mitchell et al, 1990) and varicella-zoster virus (VZV) (Croen et al, 1988). The available models share a similar basic approach (Fraser et al, 1984): peripheral (eg cornea, pinna of the ear, etc) inoculation results in transport of viral particles to the respective sensory ganglia and to the central nervous system (CNS) where replication takes place. When replication ceases, the animal tissues may be examined for the various aspects of the latent state. The animal models made it possible to break down the continuous process of HSV-1 latency into several stages which can be 
studied separately: (1) viral replication at the peripheral site of infection; (2) transport of viral particles to the nervous system; (3) establishment of latent infection; (4) maintenance of the latent state for the entire life of the host; and (5) reactivation.

\section{Viral structure and replication in cell culture}

The entire double stranded $152 \mathrm{~kb}$ DNA genome of HSV-1 (Figure 1a) has been sequenced (McGeoch et al, 1986; 1988; Perry and McGeoch, 1988) and most of its gene products have been characterized for structure and function (Roizman and Sears, 1990). The mature virion includes a tegument layer located between the capsid and the envelope. Replication of herpes DNA and the assembly of the viral capsid take place within the nucleus of the infected cell during a highly coordinated process with temporal synthesis of viral gene products according to function (for reviews see Roizman and Sears, 1987; 1990). HSV-1 genes are roughly divided into three groups: immediate early (IE) or $\alpha$ genes which are activated by a tegument structural protein Vmw65 (Batterson and Roizman, 1983; Campbell et al, 1984); genes which encode for enzymes involved in nucleotide metabolism (early, $\beta$ genes), that are activated by $\alpha$ genes; and late $(\gamma)$ genes, which mainly code for structural proteins. During productive HSV-1 infection the infected cells undergo major structural and biochemical alterations that ultimately culminate in their destruction. However, it has been suggested that the expression of $\alpha$ genes alone may not be deleterious to the host (Roizman and Sears, 1987; Morhan et al, 1989).

\section{Primary infection and establishment of latency}

How does the viral genome reach the nervous system?

Following peripheral inoculation and viral replication, HSV-1 DNA can be detected in the respective innervating PSG. However, HSV-1 replication at the peripheral site of primary infection is not a prerequisite for the ability of HSV-1 to reach the PSG (Efstathiou et al, 1989; Steiner et al, 1990). With or without peripheral replication, the timing of viral DNA appearance at the PSG suggests that following virion attachment to axonal terminals it is the fast retrograde axonal flow which mediates viral transport to the nerve cell body (Cook and Stevens, 1973; Kristensson et al, 1986).

The prevention of HSV-1 replication as a key to the establishment of latency

Once HSV-1 reaches the PSG, it can resume replication. However, replication will cause host cell destruction while factors, viral or cellular, which will prevent replication will enable the cell to survive and host the latent viral genome in the tissue, thus favouring the establishment of latency. Indeed, prevention of replication by passive immunization prior to ocular infection results in decreased detectable peripheral replication of virus, but increases the amount of viral DNA and the number of latently infected neurons in PSG via an unknown mechanism (Birmanns et al, 1993). It is noteworthy, therefore, that while most human adults are seropositive for HSV, and up to $61 \%$ of them have recurrent mucocutaneous disease, only less than $5 \%$ have a history of clinical primary disease (Whitley, 1985), suggesting that viral replication may not take place during all primary HSV-1 infections. Several factors can prevent replication or abort it prior to host cell destruction. Most of them are not an absolute prerequisite for the ability of HSV-1 to establish latent infection, and some of them may act in concert to enable the establishment of latency.

Viral factors which favour establishment of latency Vmw65 may play a pivotal role in the outcome of HSV-1 infection and the ability of the virus to enter a latent state (Steiner et al, 1990; Steiner and Kennedy, 1991). During attachment of HSV-1 virions to the axonal membrane, the virus loses its envelope, and therefore, part of the content of the tegument, Vmw65 included, may be lost during viral transport to the neuronal nucleus (Lycke et al, 1984,1988 ). The amount of Vmw65 reaching the nucleus is one determinant of whether a lytic replication cycle will ensue. Indeed, lack of functional Vmw65 was associated with higher proportion of latently infected neurons (Steiner et al, 1990). However, the presence of Vmw65 by itself does not prevent the establishment of latency (Sears et al, 1991). Another factor which might influence the ability of HSV-1 to replicate and therefore affect the formation of a latent infection, is the amount of inoculated virus (Fraser et al, 1991). This is analogous to the ability to overcome a defect in replication of a mutant virus in cells in culture by increasing the multiplicity of infection (MOI). It might be of special relevance in certain cells, eg neurons, which possess mechanisms to prevent HSV-1 replication and are therefore relatively non-permissive for HSV-1 replication.

The non-permissiveness of neurons for HSV-1 replication as favouring the establishment of latent infection

Several reports suggested that neurons, at least in culture, express factors which have an inhibitory effect upon expression of HSV-1 IE genes (Ash, 1986; Kemp et al, 1990; Wheatley et al, 1991; Lillycrop et al, 1993), and therefore arrest HSV-1 replication at an early stage prior to irreversible cell damage. One of these factors is Oct-2, a transcrip- 
tional factor expressed at high levels in nerve cells. By binding to a protein complex containing Vmw65 it can inhibit the IE activation activity of Vmw65 (Lillycrop et al, 1993). Thus, increasing the. MOI will diminish the repressor activity of Oct-2 by increasing the relative amount of Vmw65 and leading eventually to initiation of the HSV-1 replication cascade.

\section{The role of the immune system}

Immunization of mice with hyper immune serum prior to primary infection, prevents replication and increases the number of latently infected neurons (Birmanns et al, 1993). Several mechanisms might be responsible for this observation: antibodies can bind to HSV-1 infected neurons and downregulate intracellular viral replication (Oaks and Lausch, 1984), and CD8+ $T$ cells can terminate viral gene expression in neurons without cytolysis (Simmons and Tscharke, 1992). However, latent infection can be formed in immunodeficient mice (Moriyama et al, 1992; Valyi Nagy et al, 1992), suggesting that while the immune mechanisms might contribute to the establishment of latent HSV-1 infection they are not absolutely required.

\section{Molecular phenomena of HSV-1 latency}

\section{DNA structure, location and organization}

The entire HSV-1 genome is present in latently infected nervous tissue, but the ends within the terminal repeats (Figure 1a) are present in amounts suggesting that the latent HSV-1 DNA is maintained either as a circular molecule or in a concatameric form (Rock and Fraser, 1983, 1985; Efstathiou et al, 1986). The viral DNA is not integrated into the host cell genome (Mellerick and Fraser, 1987), and is organized in a structure similar in pattern to host nuclear chromatin (Deshmane and Fraser, 1989). The amount of viral DNA per latently infected cell is unknown but it might be relevant to the mechanisms of latency and reactivation, since it has been suggested (Roizman and Sears, 1987; Fraser et al, 1991) that a smaller number of viral DNA copies per cell is associated with inability to initiate replication within the nucleus and a larger copy number will facilitate reactivation.

\section{Gene expression}

No infectious viral particles are present during latent infection. Therefore, the discovery of latent phase HSV-1 transcriptional activity has stimulated intensive research aimed at mapping and characterizing HSV-1 latency-associated genes and elucidation of their function. The viral latency-associated transcription stems from a $10.4 \mathrm{~kb}$ fragment within the repeat regions (Figure 1b) (Stevens et al, 1987; Deatly et al, 1987; Croen et al, 1987; Steiner et al,
1988; Gordon et al, 1988; Stevens et al, 1988), but only a $2.0 \mathrm{~kb}$ subfragment synthesizes two mRNAs, 2.0 and $1.5 \mathrm{~kb}$ in size, which are abundant enough to be studied by Northern blot analysis (Spivack and Fraser 1987; Steiner et al, 1988; Krause et al, 1988). These latency-associated transcripts (LATs) are transcribed in the opposite direction to the IE gene ICPO (Figure 1b-c) and overlap its mRNA3 end by approximately $700 \mathrm{bp}$. Only the $2.0 \mathrm{~kb}$ LAT can be identified during viral replication in cell culture, and in much smaller amounts than those present during latency (Spivack and Fraser 1987; Krause et al, 1988; Spivack and Fraser, 1988b). The LATs have several unique features: (1) they do not belong to any of the three viral gene classes as characterized during viral replication in cell culture (Spivack and Fraser, 1988b); ${ }^{56}$ (2) they accumulate during latency (Spivack and Fraser, 1988a, b) and by in situ hybridization can be demonstrated mainly or exclusively on and around the nucleus of the infected cell (Stevens et al, 1987; Croen et al, 1987; Steiner et al, 1988); (3) their promoter is located at an unusual distance from their coding sequence start site (Batchelor and O'Hare, 1990; Dobson et al, 1989; Zwaagstra et al, 1989, 1990), and its activity is increased in neuronal cells in culture (Batchelor and O'Hare, 1990, 1992; Zwaagstra et al, 1990; Devi-Rao et al, 1991). Recently, another 'cryptic' promoter at a closer location to the initiation of the LATs coding sequence was reported (Nicosia et al, 1993; Goins et al, 1994); (4) the $2.0 \mathrm{~kb}$ LAT transcript is unspliced, ie no RNA fragments (termed introns) are removed to form it (Figure 1c). The 1.5 LAT is a spliced product derived by removal of a $0.5 \mathrm{~kb}$ intron (Figure 1c) (Wagner et al, 1988b; Wechsler et al, 1988; Spivack et al, 1991), with a nucleic acid sequence at the splicing donor site of GC instead of the consensus GT (Mount, 1982). It may therefore serve as an inefficient splice signal during viral replication in cells in culture and nonneuronal tissue (Spivack et al, 1991) and be responsible for neuronal-specificity of production of the $1.5 \mathrm{~kb}$ LAT (Mador, Panet and Steiner, submitted for publication); (5) the $2.0 \mathrm{~kb} \mathrm{LAT}$, has a splice donor site around the beginning of its coding sequence (Devi-Rao et al, 1991; Farrel et al, 1991), suggesting that it is a stable intron. However, nuclear accumulation is not a characteristic of introns and it is very unusual for introns to be further processed.

Besides the LATs, additional RNAs stem from the latency-associated $10.4 \mathrm{~kb}$ transcriptionally-active region within the HSV-1 genome (Figure 1b), but their relation to the LATs is unclear. In vitro studies suggested the presence of two unstable larger transcripts, 8.3-8.5 and $6.5 \mathrm{~kb}$ in size (Dobson et al, 1989; Zwaagstra et al, 1990; Devi-Rao et al, 1991). The LATs are mainly unpolyadenylated (Spivack and Fraser, 1987; Wagner et al, 1988a), ie the several adenine nucleotides at the end of the mRNA molecule required for its transport to the cytoplasm and 
the translation into protein are missing. On the other hand, the unstable larger transcripts, when examined during viral replication in cell culture, are polyadenylated (Devi-Rao et al, 1991).

\section{Gene products}

No latent-phase HSV-1 gene products (LATs-coded or other) have been identified in vivo so far. At present, the possibility that no polypeptides are encoded by the latency-associated genes seems plausible despite the fact that at least two nucleic acid sequences that can code for a sequence of amino acids are present within the LATs (Figure 1c) (Wechsler et al, 1989; Spivack et al, 1991).

\section{Function and mechanisms of action of the latency-associated genes}

\section{Function}

A number of HSV-1 mutants defective in their ability to express LATs have been used to examine the function of the latency-associated transcriptional activity Uavier et al, 1988; Steiner et al, 1989; Ho and Mocarski, 1989; Lieb et al, 1989; Sedarati et al, 1989; Hill et al, 1990; Trousdale et al, 1991). These mutant viruses retain the ability to replicate in tissue culture and to establish and maintain a latent infection in vivo. However, a consistent viral phenotype is associated with some LAT-defective viruses: aberrant and prolonged explant reactivation and severely reduced ability for in vivo reactivation. While this may suggest that the LATs participate in the reactivation process, it is also possible that the reduced reactivation ability of LATs(-) mutants may be a consequence of establishment of latency in fewer initial sites (Sawtell and Thompson, 1992). Recent data has also shown that in latently infected mouse PSG, LATs and IE genes (the latter acting as a marker of HSV-1 reactivation) are not coexpressed by the same cells (Ecob-Prince et al, 1993a, b).

\section{Mechanisms of HSV-1 reactivation}

HSV reactivation in humans, with resultant cold sores or genital lesions, can be triggered by local stimuli (such as injury to tissues innervated by the neurons harboring latent infection) or by systemic conditions including exposure to sun, fever, emotional stress and menstruation (Hill, 1985). Even after repeated bouts of reactivation, most individuals do not exhibit permanent sensory loss or any other neurological deficit in the affected dermatomes (Gominak et al, 1990). We therefore assume that reactivation is not associated with a significant destruction of latently infected neurons and thus differs from HSV-1 lytic replication.

Two major molecular questions which might be relevant to the mechanisms of action of the latencyassociated genes are open at this point: (1) How does replication begin in the absence of $\mathrm{Vmw} 65$ protein to stimulate the early stages of the HSV-1 replication cycle? (2) How does the viral genome get to the stage of active replication at the periphery without prior destruction of the cell hosting the latent viral genome?

Viral factors Theoretically the LATs, could augment and facilitate reactivation at four different points: (1) Increasing the amount of latent viral DNA during the establishment of latency. This is supported by a study that demonstrated more latently infected cells in TG of mice infected with wild-type virus than with a LATs(-) mutant, suggesting that the LATs may in fact participate in establishment of latency (Sawtell and Thompson, 1992). (2) Releasing, or counteracting, under certain permissive circumstances, a neuronal inhibitory factor that renders the neuron relatively non-permissive to HSV-1 replication during the maintenance of latency. However, since even recurrent reactivations are not accompanied by sensory loss, it seems unlikely that reactivation is associated with HSV-1 replication in the PSG. (3) Initiation, at the periphery, of the replication cascade of HSV-1. Since Vmw65 is not expressed during latency, it seems that a crucial step in the ability of HSV-1 to reactivate is the presence of some viral or cellular factors which circumvent the initial lack of Vmw65 to activate IE gene expression. Such a function might be mediated by the latency-associated transcription. (4) Facilitating the transfer of the viral nucleic acids from the PSG via the axon to the periphery where the virus can resume replication and reactivation without damaging the nerve cells and the viral reservoir. The fact that reactivation with LATs(-) mutants, though defective, is possible with explant tissues (Steiner et al, 1989) (where axonal transport is not required) but not in vivo (Hill et al, 1990; Trousdale et al, 1991), may support the notion that LATs have a role in viral DNA transport.

As no lantency-associated gene product has been identified as yet, it is possible that these genes act via functional RNA. The end of the LATs overlaps with that of ICP0 and therefore an antisense mechanism (whereby a homologous transcript of opposing orientation binds to a mRNA and physically blocks its translation into gene products) for the LATs was proposed (Stevens et al, 1987). While this hypothesis could already be discounted on theoretical grounds, results with HSV-1 LATs(-) mutants have excluded it experimentally: the reactivation kinetics of these mutants is not stimulated as it should have been in the case of the absent antisense inhibition of ICP0, but, on the contrary, is impaired.

Cellular factors The effect of cellular factors upon reactivation and LATs expression has been examined in vitro and has yielded two interesting findings. (1) Nerve growth factor (NGF) may have a role in rendering a neuron non-permissive for viral reac- 
tivation, since it is required for the maintenance of a quasi-latent form of HSV in a neuronal cell tissue system (Wilcox and Johnson, 1987; Wilcox et al, 1990). (2) The promoter region of the LATs contains a cAMP-responsive element and administration of cAMP accelerated explant reactivation via a sequence located within the LAT promoter region (Lieb et al, 1991; Rader et al, 1993). In this case, extraneural stimuli might trigger HSV reactivation via second messenger signal transduction and cAMP action upon LATs regulatory elements.

Immune factors Immunosuppression of latently infected animals leads to HSV-1 reactivation (Birmanns et al, 1993; Openshaw et al, 1979), suggesting that immunological mechanisms are associated with maintenance of latency. However, this phenomenon is the exception, since in humans, recurrent disease usually occurs in immunocompetent hosts who are seropositive for HSV-1. Moreover, latency is maintained under conditions associated with defective T- and B-cell functions (Moriyama et al, 1992; Valyi-Nagy et al, 1992). As no viral antigens are expressed during latent infection, and the process of reactivation probably does not involve host cell destruction within the PSG, immune responses are unlikely to be evident in the PSG. On encountering mature virions at the periphery, however, the immune system may be activated.

\section{CNS latency and the source of the virus causing encephalitis}

Although HSV-1 is responsible for the viral encephalitis with the highest fatality rate, much less is known about the molecular biology of latent HSV-1 infection in the CNS than in the PNS. HSV has also been implicated in the pathogenesis of other CNS disorders such as multiple sclerosis (Kastrukoff et al, 1987), Behçet disease (Eglin et al, 1982) and Alzheimer's disease (Ball, 1982), but no conclusive evidence to link HSV (both 1 and 2) with any CNS disease other than meningoencephalitis, myelitis (Shyu et al, 1993) and Mollaret's meningitis (Yamamoto et al, 1991; Cohen et al, 1994) has been produced so far.

\section{$H S V-1$ reactivation ability from CNS tissue is extremely limited}

Following viral replication within TG in experimental animals the virus travels to, and replicates in, the CNS (Stevens, 1989), but when replication ceases, explanted brainstem tissues do not reactivate virus. Similarly, despite the presence of HSV-1 nucleic acids in the human brain (Fraser et al, 1981, and our unpublished data) we are unaware of any report of recurrent encephalitis induced by HSV-1, and attempts to reactivate HSV-1 from explanted human CNS tissue have failed. Herpes encephalitis in immunocompetent individuals is a very rare single event which is 1 million fold less frequent than the peripheral disease (Whitley, 1985). The source of the virus causing herpes encephalitis is not known. It has been suggested that encephalitis is due to HSV-1 reactivation from TG (Johnson, 1982), since the infectious process tends to involve the temporal and frontal lobes, brain regions with blood vessels and meninges which derive their sensory innervation from the TG. However, since not all cases of herpes encephalitis are caused by the same viral strain that is responsible for cold sores in the same individual (Whitley et al, 1982), it is assumed that in approximately half of the patients HSV-1 encephalitis occurs during primary viral infection (Whitley, 1990). Moreover, even in the presence of a prior HSV-1 infection, a second primary infection with another HSV-1 strain can take place and thus may be responsible for the encephalitic infection.

Several factors may be responsible for the differences between HSV-1 reactivation from the peripheral and the central nervous systems. (1) The quantity of the LATs may contribute to the efficacy of reactivation (Birmanns et al, 1993; Block et al, 1990). While the organization of the HSV-1 DNA in the brainstem and in the TG is similar (Rock and Fraser, 1983), the relative amounts of viral DNA and latency-associated gene expression in the CNS are lower than those in the PNS (Steiner et al, 1994). (2) The type of gene expression in the CNS may differ from that present in PSG. Thus, the $1.5 \mathrm{~kb}$ LAT was not detected in brainstem tissue (Steiner et al, 1994). (3) Still unknown host and CNS-specific tissue factors might inhibit viral reactivation in the CNS.

\section{A unifying scheme-the advantage of latency in nervous tissue for the virus (Figure 2)}

We suggest the following sequence of events. During primary infection, HSV-1 enters sensory nerve terminals at the peripheral site of inoculation and is transported to the nerve cell body and nucleus via fast retrograde axonal transport. In the nucleus of the neuron, prevention of lytic infection is critical for the establishment of latency. Several factors, cellular and viral, can act alone or in concert to prevent replication and enable the establishment of latency. Recent evidence even suggests that neurons may have a unique ability to survive viral infections by blocking programmed cell death (Levine et al, 1993). Both the establishment of latency and the latency-associated restricted gene expression take place at a very early stage, following arrival of the viral genome in the nucleus.

The unique ability of neurons to transport molecules away from their cell body to other tissues and distant body regions, and from the periphery into the neuronal soma, has an obvious advantage for 


\section{Peripheral Sensory Ganglia}

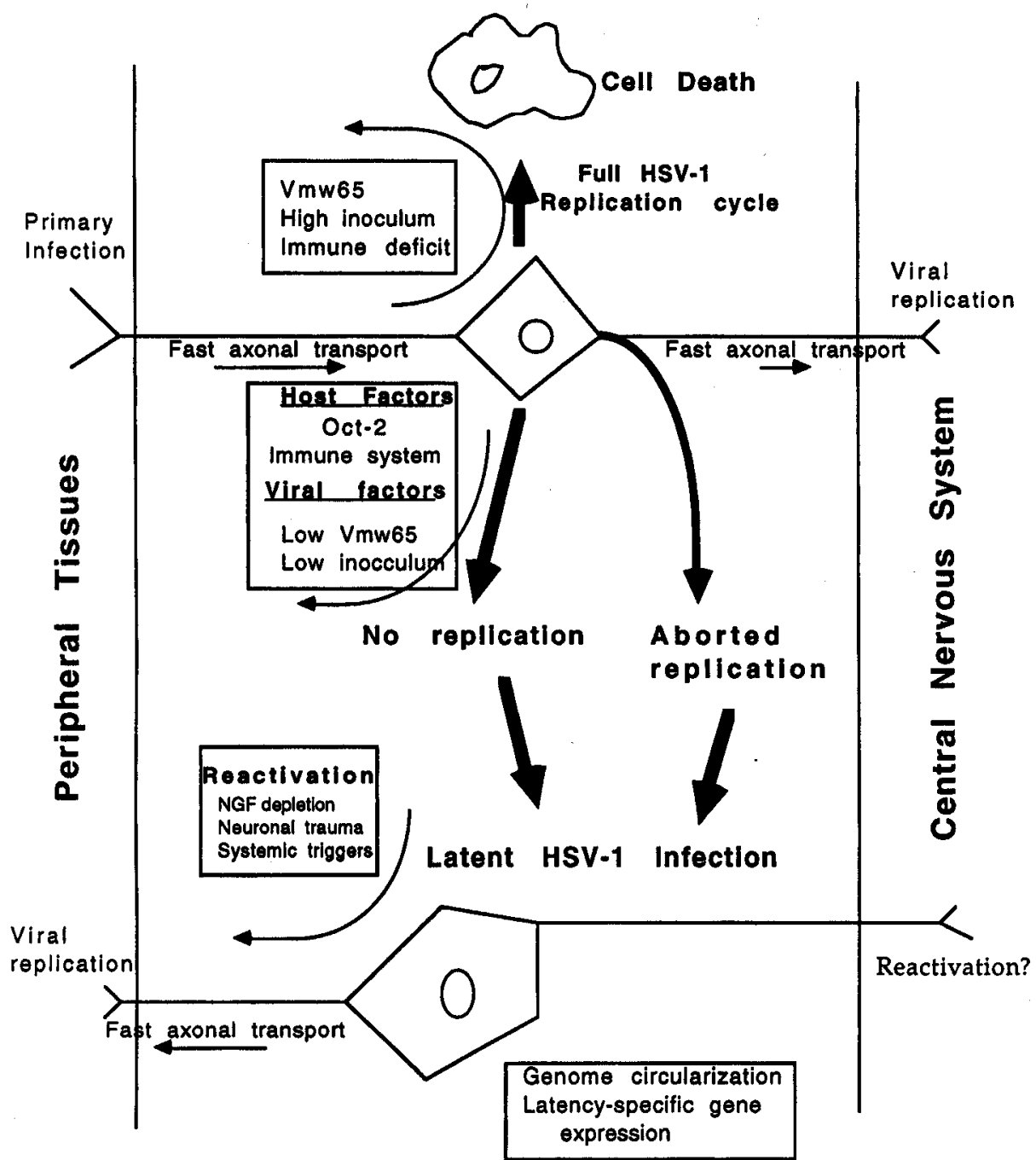

Figure 2 Schematic illustration of herpes simplex virus replication cycle and possible mechanisms of latent infection in the nervous system of animals. Following primary infection at peripheral mucocutaneous tissues, the virion travels via fast axonal transport to peripheral sensory ganglia (PSG). Under certain conditions which favour viral replication, such as high levels of Vmw65, high amount of inoculated virus and defective immune mechanisms, a full replication cycle will ensue, leading to neuronal cell death. By constrast, an effective immune system, low levels of Vmw65, low amounts of inoculated virus and neuronal-specific factors such as Oct-2 will prevent viral replication and could lead to the establishment of latent infection. Neurons are also capable of aborting HSV replication at a stage which will not lead to cell death and enable the formation of latent HSV-1 infection. Following primary infection, HSV is also able to travel to the central nervous system (CNS) and replicate there. During latency HSV-1 genome is 'endless' and latency-specific gene expression takes place. Under specific systemic and local triggers the latent genome can reactivate, travel to the periphery and replicate there. The ability of HSV-1 to reactivate and travel to the CNS is uncertain.

the survival of HSV-1. It makes it possible physically to separate the site of active viral replication in the mucocutaneous tissues from the neuronal cell body, which serves as the permanent reservoir of viral DNA, and remains undamaged. Viral replication in the peripheral mucocutaneous tissues enables the spread of infection to other carriers.
While it is possible that viral DNA is transported from PSG to the CNS as well as to the periphery, reactivation of HSV-1 DNA does not occur in the CNS (unlike replication, when a replication competent virus reaches CNS tissue). It is therefore likely that HSV-1 encephalitis is due either to primary infection in a rare case of a seronegative individual, 
or due to an infection with another, HSV-1 strain, rather than reactivation of latent virus from the trigeminal ganglia.

The role of the HSV-1 LATs in reactivation is not entirely clear. The LATs might act to stimulate host functions required for reactivation, or conversely, to inhibit the synthesis of host factors that suppress reactivation. Alternately, they may replace Vmw65 protein function and initiate IE expression. Another possibility is that the LATs may promote the migration of latent viral DNA out of the neuronal nucleus, into the cytoplasm and the axon. Further research is required to establish the role of the latency-associated gene expression in the HSV-1 latency process, and we anticipate significant advances in the understanding of HSV latency at the molecular level over the next few years. The extent to which such advances will enhance our

\section{References}

Abgharis SZ, Stulting RD (1988). Recovery of herpes simplex virus from ocular tissues of latently infected inbred mice. Invest Ophthalmol Visual Sci 29: 239-243.

Ash RJ (1986). Butyrate-induced reversal of herpes simplex virus restriction in neuroblastoma cells. Virology 155: 584-592.

Ball MJ (1982). Limbic predilection in Alzheimer dementia: is reactivated herpesvirus involved? Can $J$ Neurol Sci 9: 303-306.

Baringer JR, Swoveland P (1973). Recovery of herpes simplex virus from human trigeminal ganglions. $N$ Engl JMed 288: 648-650.

Bastian RO, Rabson AS, Yee CL, Tralka TS (1972). Herpes virus huminis: isolation from human trigeminal ganglia. Science 178: 306-307.

Batchelor AH, O'Hare P (1990). Regulation and cell-typespecific activity of a promoter located upstream of the latency-associated transcript of herpes simplex virus type 1. J Virol 64: 3269-3279.

Batchelor AH, O'Hare P (1992). Localization of cis-acting sequence requirements in the promoter of the latencyassociated transcript of herpes simplex virus type 1 required for cell type specific activity. J Virol 66: 3563-3582.

Batterson W, Roizman B (1983). Characterization of the herpes simplex virion-associated factor responsible for the induction of $\alpha$ genes. J Virol 46: 371-377.

Birmanns B, Reibstein I, Steiner I (1993). Characterization of an in vivo reactivation model of herpes simplex virus from mice trigeminal ganglia $J$ Gen virol 74: 2487-2491.

Block TM, Spivack JG, Steiner I, Deshmane S, McIntosh MT, Lirette RP, Frazer NW (1990). A herpes simplex virus type 1 latency-associated transcript mutant reactivates with normal kinetics from latent infection. $J$ Virol 64: 3417-3426.

Campbell MEM, Palfreyman JW, Preston GM (1984). Identification of herpes simplex virus DNA sequences which encode a trans-acting polypeptide responsible for stimulation of immediate early transcription. $/ \mathrm{Mol}$ Biol 180: 1-19. understanding of HSV-associated neurological diseases such as HSV encephalitis remains uncertain.

\section{Acknowledgements}

We are greatly indebted to Drs B Birmanns and D Soffer, Jerusalem, Israel, for critical reviewing of the manuscript and helpful suggestions. Work in the field by IS was supported in part by grant No 88-00184 from the United States-Israel Binational Science Foiundation (BSF), Jerusalem, Israel, grants by the Chief Scientist, Ministry of Health and the Israel Cancer Association and by funds from a bequest by the Schmidt estate to the Oregon Brain Bank (MJ Ball, Director), at Oregon Health Science University, Portland, Oregon. PGEK, is a scholar in residence at the Fogarty International Center for Advanced Study in the Health Sciences, National Institutes of Health, Bethesda, Maryland, USA.

Clements GB, Subak-Sharpe J (1988). Herpes simplex virus type 2 establishes latency in the mouse foodpad. J Gen Virol 89: 375-383.

Cohen BA, Rowley AH, Long CM (1994). Herpes simplex type 2 in a patient with Mollaret's meningitis: demonstration by polymerase chain reaction. Ann Neurol 35: 112-116.

Cook ML, Stevens JG (1973). Pathogenesis of herpetic neuritis and ganglionitis in mice: Evidence of intraaxonal transport of infection. Infect Immun 7: 272-288.

Croen KD, Ostrove JM, Dragovic LJ, Smialek JE, Straus SE (1987). Latent herpes simplex virus in human trigeminal ganglia. Detection of an immediate early gene 'anti-sense' transcription by in situ hybridization. N Engl J Med 317: 1427-1432.

Croen KD, Ostrove JM, Dragovic LJ, Straus SE (1988). Patterns of gene expression and sites of latency in human nerve ganglia are different for varicella-zoster and herpes simplex viruses. Proc Natl Acad Sci USA 85: $9773-9777$.

Deatly AM, Spivack JG, Lavi E, Fraser NW (1987) RNA from an immediate early region of the type 1 herpes simplex virus genome is present in the trigeminal ganglia of latently infected mice. Proc Natl Acad Sci USA 84: 3204-3208.

Deshmane SL, Fraser NW (1989). During latency, herpes simplex virus type 1 DNA is associated with nucleosomes in a chromatin structure. J Virol 63: 943-947.

Devi-Rao GB, Goodart SA, Hecht LM, Rochford R, Rice MK, Wagner EK (1991). Relationship between polyadenylated and nonpolyadenylated herpes simplex virus type 1 latency-associated transcripts. J Virol 65: 2179-2190.

Dobson AT, Sedarati F, Devi-Rao G, Flanagan WM, Farrell MJ, Stevens JG, Wagner EK Feldman LT (1989). Identification of the latency-associated transcript promoter by expression of rabbit beta-globin mRNA in mouse sensory nerve ganglia latently infected with a recombinant herpes simplex virus. I Virol 63: 3844-3851.

Ecob-Prince MS, Preston CM, Rixon FJ, Hassan K, 
Kennedy PGE (1993a). Neurons containing latencyassociated transcripts are numerous and widespread in dorsal root ganglia following footpad inoculation of mice with herpes simplex virus type 1 mutant in1814. J Gen Virol 74: 985-994.

Ecob-Prince MS, Rixon FJ, Preston CM, Hassan K, Kennedy PGE (1993b). Reactivation in vivo and in vitro of herpes simplex virus from mouse dorsal root ganglia which contain different levels of latency-associated transcripts. J Gen Virol 74: 995-1002.

Efstathiou S, Minson AC, Field HJ, Anderson JR, Wildy P (1986). Detection of herpes simplex virus-specific DNA sequences in latently infected mice and in humans. $I$ Virol 57: 446-455.

Efstathiou S, Kemp S, Darby G, Minson AC (1989). The role of herpes simplex virus type 1 thymidine kinase in pathogenesis. J Gen Virol 70: 869-879.

Eglin RP, Lehner T, Subak-Sharpe JH (1982). Detection of RNA complementary to herpes simplex virus in mononuclear cells from patients with Behçet's syndrome and recurrent oral ulcers. Lancet 2 : 1356-1361.

Farrell MJ, Dobson AT, Feldman LT (1991). Herpes simplex virus latency-associated transcript is a stable intron. Proc Natl Acad Sci USA 88: 790-794.

Fraser NW, Lawrence NC, Wroblewska Z, Gilden DH, Koprowski $H$ (1981). Herpes simplex virus type 1 DNA in human brain tissue. Proc Natl Acad Sci USA 78: 6461-6465.

Fraser NW, Muggeridge MI, Mellerick DM, Rock DL (1984). Molecular biology of HSV-1 latency in a mouse model system, In: Rapp F (ed). Herpesvirus. Alan R. Liss Inc: New York, pp 159-173.

Fraser NW, Spivack JG, Wroblewska Z, Block T, Deshmane SL, Valyi-Nagy T, Natarajan R, Gesser RM (1991). A review of the molecular mechanism of HSV-1 latency. Curr Eye Res 10(Suppl): 1-14.

Goins WF, Sternberg LR, Groen KD, Krause PR, Hendricks RL, Fink DJ, Straus SE, Levine M, Glorioso JC (1994). A novel latency-active promoter is contained within the herpes simplex type 1 UL flanking repeats. J Virol 68: 2239-2252.

Gominak S, Cros D, Paydarfar D (1990). Herpes simplex labialis and trigeminal neuropathy. Neurology 40: 151-152.

Goodpasture EW (1929). Herpetic infections with special reference to involvement of the nervous system. Medicine 8, 223-243

Gordon YJ, Johnson B, Romanowski E, Araullo-Cruz T (1988). RNA complementary to herpes simplex virus type 1 ICPO gene demonstrated in neurons of human trigeminal ganglia. I Virol 62: 1832-1835.

Hill TJ (1985). Herpes simplex virus latency. In: Roizman B (ed). The Herpes Viruses. Vol 3. Plenum Publishing Corp: New York, pp 175-240.

Hill JM, Sedarati F, Javier RT, Wagner EK, Stevens JG (1990). Herpes simplex virus latent phase transcription facilitates in vivo reactivation. Virology 174: 17-125.

Ho DY, Mocarski ES (1989). Herpes simplex virus latent RNA (LAT) is not required for latent infection in the mouse. Proc Natl Acad Sci USA 86: 7596-7600.

Javier RT, Stevens JG, Dissette VB, Wagner EK (1988). A herpes simplex virus transcript abundant in latently infected neurons is dispensable for establishment of the latent state. Virology 166: 254-257.

Johnson RT (1982). Viral Infections of the Nervous
System. Raven Press: New York, pp 129-157.

Kastrukoff LF, Lau AS, Kim SU (1987). Multifocal CNS demyelination following peripheral inoculation with herpes simplex virus type 1. Ann Neurol 22: 52-59.

Kaye SB, Patterson A, Risk JM, McCarthy K, Hart CA (1991). Evidence for herpes simplex viral latency in the human cornea. Br J Ophthalmol 75: 195-200.

Kemp LM, Dent CL, Latchman DS (1990). Octamer motif mediates transcriptional repression of HSV immediate early genes and octamer-containing cellular promoters in neuronal cells. Neuron 4: 215-222.

Kennedy PGE, Steiner I (1993). The use of herpes virus vectors for gene therapy in neurological diseases. $Q J$ Med 11: 697-702.

Krause PR, Croen KD, Straus SE, Ostrove JM (1988). Detection and preliminary characterization of herpes simplex virus type 1 transcripts in latently infected human trigeminal ganglia. J Virol 62: 4819-4823.

Kristensson K, Lycke E, Roytta M, Svennerholm B, Vahlne A (1986). Neuritic transport of herpes simplex in rat sensory neurons in vitro. Effects of substances interacting with microtubular function and axonal flow (nocodazole, taxol, and erythro-9-3-(2-hydroxynonyl)adenine). J Gen Virol 67: 2023-2028.

Levine B, Huang Q, Isaacs JT, Reed JC, Griffin DE, Hardwick JM (1993). Conversion of lytic to persistent alphavirus infection by the bcl-2 cellular oncogene. Nature 361: 739-742.

Lieb DA, Bogard CL, Kosz-Vnenchak M, Hicks KA, Coen DM, Knipe DM, Schaffer PA (1989). A deletion mutant of the latency-associated transcript of herpes simplex virus type 1 reactivates from latent state with reduced frequency. J Virol 63: 2893-2900.

Lieb DA, Nadeau KC, Rundle SA, Schaffer PA (1991). The promoter of the latency-associated transcripts of herpes simplex virus type 1 contains a functional cAMPresponse element: Role of ther latency-associated transcripts and cAMP in reactivation of viral latency. Proc Natl Acad Sci USA 88: 48-52.

Lillycrop KA, Estridge JK, Latchman DS (1993). The octamer binding protein Oct-2 inhibits transactivation of the herpes simplex virus immediate-early genes by the virion protein Vmw65. Virology 196: 888-891.

Lycke E, Kristensson K, Svennerholm B, Vahlne A, Ziegler R (1984). Uptake and transport of herpes simplex virus in neurites of rat dorsal root ganglia cells in culture. J Gen Virol 65: 55-64.

Lycke E, Hamark B, Johansson M, Krotochwil A, Lycke J, Svennerholm B (1988). Herpes simplex virus infection of the human sensory neuron. An electron microscopy study. Arch Virol 101: 87-104.

McGeoch DJ, Dolan A, Donald S, Brauer DHK (1986). Complete DNA sequence of the short repeat region in the genome of herpes simplex virus type 1. Nucleic Acids Res 14: 1727-1745.

McGeoch DJ, Dalrymple MA, Davison AJ, Dolan A; Frame MC, McNab D, Perry LJ, Scott JE, Taylor P (1988). The complete DNA sequence of the long unique region in the genome of herpes simplex virus type 1. J Gen Virol 69: 1531-1574.

Mellerick DM, Fraser NW (1987). Physical state of the latent herpes simplex virus genome in mouse model system. Evidence suggesting an episomal state. Virology 158: 265-275.

Mitchell WJ, Deshmane SL, Dolan A, McGeoch DJ, Fraser NW (1990). Characterization of herpes simplex virus 
type 2 transcription during latent infection of mouse trigeminal ganglia. J Virol 64: 5342-5348.

Morhan PS, Mama S, Anaraki F, Leary K (1989). Molecular localization of abortive infection of resident peritoneal macrophages by herpes simplex virus type 1 . $J$ Virol 63: 2300-2307.

Moriyama K, Mohri S, Watanabe T, Mori R (1992). Latent infection of SCID mice with herpes simplex virus 1 and lethal cutaneous lesions in pregnancy. Microbiol Immunol 36: 841-853.

Mount SM (1982). A catalogue of splice junction sequences. Nucleic Acids Res 10: 459-472.

Nicosia M, Deshmane ZL, Zabolotny JM, Valyi-Nagy T, Fraser NW (1993). Herpes simplex virus type 1 latencyassociated transcript (LAT) promoter deletion mutants can express a 2- kilobase transcript mapping to the LAT region. J Virol 67: 7276-7283.

Oaks JE, Lausch RN (1984). Monoclonal antibodies suppress replication of herpes simplex virus type 1 in trigeminal ganglia. J Virol 51: 656-661.

Openshaw H, Shavrina-Asher LW, Wohjenberg C, Sekizawa T, Notkins AL (1979). Acute and latent infection of sensory ganglia with herpes simplex virus: immune control and virus reactivation. J Gen Virol 44: 205-215.

Perry LJ, McGeoch DJ (1988). The DNA sequences of the long repeat regions and adjoining parts of the long unique region in the genome of herpes simplex virus type 1. J Gen Virol 69: 2831-2846.

Rader KA, Ackland-Berglund CE, Miller JK, Pepose JS, Lieb DA (1993). In vivo reactivation of site-directed mutations in the promoter of the herpes simplex virus type 1 latency-associated transcripts. J Gen Virol 74: 1859-1869.

Rock DL, Fraser NW (1983). Detection of HSV-1 genome in the central nervous system of latently infected mice. Nature 302: 523-525.

Rock DL, Fraser NW (1985). Latent herpes simplex virus type 1 DNA contains two copies of the virion DNA joint region. J Virol 55: 849-852.

Roizman B, Sears AE (1987). An inquiry into the mechanisms of herpes simplex virus latency. Ann Rev Microbiol 41: 543-571.

Roizman B, Sears AE (1990). Herpes simplex viruses and their replication. In: Fields BN et al (eds). Virology. 2nd edn. Raven Press Ltd: New York, pp 1795-1841.

Sawtell NM, Thompson RL (1992). Herpes simplex virus type 1 latency-associated transcription unit promotes anatomical site-dependent establishment and reactivation from latency. I Virol 66: 2157-2169.

Sears AE, Hukkanen V, Labow MA, Levine AJ, Roizman B (1991). Expression of the herpes simplex virus type 1 transinducing factor does not induce reactivation of latent virus or prevent the establishment of latency in mice. J Virol 65: 2929-2935.

Sedarati F, Izumi KM, Wagner EK, Stevens JG (1989). Herpes simplex virus type 1 latency-associated transcription plays no role in establishment or maintenance of a latent infection in murine sensory neurons. J Virol 63: 4455-4458.

Shyu WC, Lin JC, Chang B-C, Harn H-J, Lee C-C, Tsao W-L (1993). Recurrent ascending myelitis: an unusual presentation of herpes simplex virus type infection. Ann Neurol 34: 625-627.

Simmons A, Tscharke DC (1992). Anti-CD8 impairs clearance of herpes simplex virus from the nervous system: implication for the fate of the virally infected neurons. J Exp Med 175: 1337-1344.

Spivack JG, Fraser NW (1987). Detection of herpes simplex type 1 transcripts during latent infection in mice. J Virol 61: 3841-3847.

Spivack JG, Fraser NE (1988a). Expression of herpes simplex type 1 (HSV-1) latency-associated transcripts and transcripts affected by the deletion in avirulent mutant HFEM: Evidence for a new class of HSV-1 genes. J Virol 62: 3281-3287.

Spivack JG, Fraser NW (1988b). Expression of herpes simplex virus type 1 latency-associated transcripts in the trigeminal ganglia of mice during acute infection and reactivation of latent infection. J Virol 62: 1479-1485.

Spivack JG, Woods GM, Fraser NW (1991). Identification of a novel latency-specific splice donor signal within the herpes simplex virus type 12.0 -kilobase latencyassociated transcript (LAT); translation inhibition of LAT open reading frames by the intron within the 2.0kilobase LAT. J Virol 65: 6800-6810.

Steiner I, Spivack JG, O'Boyle DR, Lavi E, Fraser NW (1988). Latent herpes virus type 1 transcription in human trigeminal ganglia. J Virol 62: 493-496.

Steiner I, Spivack JG, Lirette RP, Brown SM, MacLean AR, Subak-Sharpe J, Fraser NW (1989). Herpes simplex virus type 1 latency-associated transcripts are evidently not essential for latent infection. EMBO J 8: 505-511.

Steiner I, Spivack JG, Deshmane SL, Ace CI, Preston CM, Fraser NW (1990). A herpes simplex virus type 1 mutant containing a non-transinducing Vmw65 protein establishes latent infection in vivo in the absence of viral replication and reactivates efficiently from explanted trigeminal ganglia. J Virol 64: 1630-1638.

Steiner I, Kennedy PGE (1991). Herpes simplex virus latency in the nervous system-a new model. Neuropathol Appl Neurobiol 17: 433-440.

Steiner I, Kennedy PGE (1993). The molecular biology of herpes simplex virus type 1 latency in the nervous system. Mol Neurobiol 7: 137-159.

Steiner I, Mador N, Reibstein I, Spivack JG, Fraser NW (1994). Herpes simplex virus type 1 latency in human and mouse central nervous systems. Neuropathol Appl Neurobiol 20: 253-260.

Stevens JG (1978). Latent characteristics of selected herpesviruses. Adv Cancer Res 26: 227-256.

Stevens JG (1989). Human herpesviruses: a consideration of the latent state. Microbiol Rev 53: 318-322.

Stevens JG, Cook ML (1971). Latent herpes simplex virus in spinal ganglia of mice. Science 173: 843-845.

Stevens JG, Wagner EK, Devi-Rao GB, Cook ML, Feldman LT (1987). RNA complementary to a herpesvirus alpha gene mRNA is prominent in latently infected neurons. Science 235: 1056-1059.

Stevens JG, Haarr L, Porter DD, Cook ML, Wagner EK (1988). Prominence of the herpes simplex virus latencyassociated transcript in trigeminal ganglia from seropositive humans. J Infect Dis 158: 17-22.

Trousdale MD, Steiner I, Spivack JG, Deshmane SL, Brown SM, MacLean AR, Subak-Sharpe JH, Fraser NW (1991). In vivo and in vitro reactivation impairment of a herpes simplex virus type 1 latency-associated transcript variant in a rabbit eye model. $J$ Virol 65: 6989-6993.

Valyi-Nagy T, Deshmane SL, Raengsakulrach B, Nicosia M, Gesser RM, Wysocka M, Dillner A, Fraser NW 
(1992). Herpes simplex virus type 1 mutant strain in 1814 establishes a unique, slowly progressing infection in SCID mice. J Virol 66: 7336-7345.

Wagner EK, Devi-Rao G, Geldman LT, Dobson AT, Zhang Y-F, Flanagan WM, Stevens JG (1988a). Physical characterization of the herpes simplex virus latencyassociated transcripts in neurons. I Virol 62: 1194-1202.

Wagner EK, Flanagan WM, Devi-Rao G, Zhang Y-F, Hill JM, Anderson KP, Stevens JG (1988b). The herpes simplex virus latency-associated transcript is spliced during the latent phase of infection. $J$ Virol 62: 4577-4585.

Wechsler SL, Nesburn AB, Watson R, Slanina SM, Ghiasi $H$ (1988). Fine mapping of the latency-related gene of herpes simplex virus type 1: alternating splicing produces distinct latency-related RNAs containing open reading frames. J Virol 62: 4051-4058.

Wechsler SL, Nesburn AB, Watson R, Zwaagstra J, Ghiasi $H$ (1989). Sequence of the latency-related gene of herpes simplex virus type 1 . Virology 168: 168-172.

Wheatley SC, Dent CL, Wood JN, Latchman DS (1991). A cellular factor binding to the TAATGARAT DNA sequence prevents the expression of the HSV immediate-early genes following infection of nonpermissive cell lines derived from dorsal root ganglion neurons. Exp Cell Res 194: 78-82.

Whitley RJ (1985). Epidemiology of herpes simplex viruses. In: Roizman B (ed). The Herpes Viruses. Vol 3.
Plenum Publishing Corp: New York. pp 1-44.

Whitley RJ (1990). Herpes simplex viruses. In: Fields BN et al (eds). Virology. 2nd edn. Raven Press Ltd: New York, pp 1843-1886.

Whitley R, Lakeman AD, Nahmias A, Roizman B (1982). DNA restriction-enzyme analysis of herpes simplex virus isolates obtained from patients with encephalitis. N Engl J Med 307: 1060-1062.

Wilcox CL, Johnson EM (1987). Nerve growth factor deprivation results in reactivation of latent herpes simplex virus in vitro. $J$ Virol 61: 2311-2315.

Wilcox CL, Smith RL, Freed CR, Johnson EM (1990). Nerve growth factor-dependence of herpes simplex virus latency in peripheral sympathetic and sensory neurons in vitro. $J$ Neurosci 10: 1268-1275.

Yamamoto LJ, Tedderm DG, Ashley R, Levin MJ (1991). Herpes simplex virus type 1 in the cerebrospinal fluid of a patient with Mollaret's meningitis. $N$ Engl $J$ Med 325: 1082-1085.

Zwaagstra JC, Ghaisi H, Nesburn AB, Wechsler SL (1989). In vitro promoter activity associated with the latencyassociated transcript gene of herpes simplex virus type 1. J Gen Virol 70: 2163-2169.

Zwaagstra JC, Ghaisi H, Slanina SM, Nesburn AB, Wheatley SC, Lillycrop K, Wood J, Latchman DS, Patel $\mathrm{K}$, Wechsler SL (1990). Activity of herpes simplex virus type 1 latency-associated transcript (L.AT) promoter in neuron-derived cells: evidence for neuron specificity and for a large LAT transcript. J Virol 64: 5019-5028. 